\title{
INVESTIGACIONES
}

\section{Producción de conocimientos espacio-corporales en la enseñanza de la danza*}

\author{
Production of space-corporal knowledge in dance teaching
}

\author{
Nataly Pérez-Cisternas ${ }^{a}$ \\ ${ }^{a}$ Facultad de Educación. Pontificia Universidad Católica de Chile. \\ naperez2@uc.cl
}

\section{RESUMEN}

Esta revisión crítica de literatura pretende develar cómo se está produciendo conocimiento espacio-corporal en la enseñanza de la danza actualmente. Para esto se realizó una revisión de los artículos publicados entre los años 2001 y 2016 en las bases de datos Web of Science, Scopus y Scielo. Se revisaron 40 artículos a partir de cuatro categorías de análisis asociadas a los siguientes ámbitos: institucional/curricular, educación primaria y secundaria, educación superior, y enseñanza no formal. Uno de los resultados más importantes es que efectivamente se prioriza la visión dominante, binaria y asimétrica, que propone la primacía del tiempo y la mente, por sobre el espacio y el cuerpo en los procesos de enseñanza dancística más arraigados a una formación tradicional. Sin embargo, en los últimos años, existe mayor producción de investigaciones empíricas que intencionan una aproximación hacia la enseñanza de los conocimientos espacio-corporales de forma menos fragmentada.

Palabras claves: Producción de conocimientos, conocimiento espacial, conocimiento corporal, enseñanza de la danza.

\section{ABSTRACT}

This critical review of literature aims to unveil how space-corporal knowledge is being produced in dance teaching today. For this purpose, a review of articles published between 2001 and 2016 in the Web of Science, Scopus and Scielo databases was carried out. Forty articles were reviewed from four categories of analysis associated with the following areas: institutional/curricular, primary and secondary education, higher education, and non-formal education. One of the most important results is that the dominant, binary and asymmetric vision, which proposes the primacy of time and mind over space and body, is effectively prioritized in the dance teaching processes more rooted in a traditional formation. However, in recent years, there has been a greater production of empirical research aimed at a less fragmented approach to the teaching of space-body knowledge.

Key words: Knowledge production, Spatial knowledge, Body knowledge, Dance teaching.

\footnotetext{
* Este artículo es producto de la revisión de literatura desarrollada para la investigación doctoral de la autora. Financiada por la beca doctorado nacional CONICYT, Chile.
} 


\section{INTRODUCCIÓN}

Cuando se plantea la discusión sobre el conocimiento, se suele mantener una mirada tradicional que supone una visión absoluta, es decir, que existe un conocimiento legítimo (Foucault, 2008). Cualquier tipo de conocimiento que se distancie de aquel que se encuentra legitimado, inmediatamente es asociado a falsedad u error. En esta lógica predominante, el conocimiento espacial es enseñado desde la instalación binaria y asimétrica tiempo/ espacio, entendiendo que el espacio se encuentra subordinado al tiempo. Mientras el conocimiento corporal es enseñado desde el binario mente/cuerpo, considerando que el cuerpo está subordinado a la mente, al raciocinio. Ambos binomios son dicotomías, que señalan que los saberes son fragmentados.

De esta forma, el conocimiento espacial y corporal es encasillado y tabulado; esta manera parcelada de ordenamiento implica una necesidad de generar categorías que permitan la aprehensión de estos saberes. Asimismo, el conocimiento entendido de esta forma mantiene una postura que erradica la multiplicidad de saberes, lo que equivale a no comprender que el conocimiento es producido por relaciones de poder (Larraín, 2014). Algunos estudios demuestran que, en el caso de la danza, la relación entre el desarrollo del conocimiento espacial y del conocimiento corporal en la enseñanza, es más bien fragmentada (Andrada \& Souza, 2015), aunque todos los bailarines entienden que esta división es procedimental, pues es imposible comprender el espacio sin cuerpo y el cuerpo sin espacio. Sin embargo, algunas investigaciones proponen el trabajo de ambos conocimientos (Tsouvala \& Magos, 2016), y esta cuestión, pareciera ser esencial para la comprensión de los procesos de enseñanza-aprendizaje de la danza, pues cuando la relación entre espacio y cuerpo se establece, pareciera ser en palabras de Grosz (1995), que está interrelación permite una comprensión visual y sensorial, las percepciones por tanto, permiten reconocer elementos asociados a la orientación y localización espacial. Lo que implica que, la enseñanza dancística no puede ser comprendida, si no se entiende el movimiento corporal en el espacio y con relación a otros cuerpos. De esta forma, la idea de representar el espacio como un continuo, estático y lineal supone no comprender la relación que establece el sujeto con estos elementos.

Algunos autores plantean (Laban, 2013; Cámara \& Islas, 2007), que para entender el movimiento es necesario comprender también el conocimiento espacial, específicamente en la relación entre espacio y cuerpo, considerando el tiempo, la energía y el flujo que se conjuga en una secuencia rítmica. Estos elementos son esenciales en la enseñanza de la danza, pues el movimiento que se trabaja en esta disciplina es un movimiento voluntario que considera una intencionalidad. Por tanto, para crear este movimiento, no solo se debe imaginar el movimiento, sino además ejecutarlo contemplando la construcción del cuerpo y del espacio. Lo anterior implica que espacio y cuerpo no pueden ser comprendidos por separado (Massey, 2008), se encuentran interrelacionados y en constante cambio.

De esta forma, se vuelve relevante la relación que se establece entre el conocimiento corporal y el conocimiento espacial, pues esta perspectiva implica entender el espacio como interrelación y multiplicidad, es decir desde su construcción y deconstrucción, por ende, serían los cuerpos que se mueven en distintos sentidos y formas, los que van posibilitando el surgimiento de nuevos espacios (McCormarck, 2008). El movimiento traducido en ritmos espaciales implicaría entender la carga emocional y afectiva con que se construye la espacialidad, y como esto necesariamente, influye en el cuerpo y su movimiento. 
Bajo estas premisas, se hace indispensable revisar si efectivamente estas discusiones están ingresando en la disciplina dancística. Por tal motivo, esta revisión crítica de literatura pretende develar cómo se está produciendo el conocimiento espacio-corporal en la enseñanza de la danza entre los años 2001 y 2016.

\section{METODOLOGÍA}

Los artículos utilizados para esta revisión crítica de literatura fueron encontrados utilizando la base de datos Web of Science y SCOPUS. Debido a que compilan las revistas más importantes con relación a la investigación en enseñanza de la danza, y al alto nivel de impacto y rigurosidad con que son revisadas y seleccionadas las publicaciones que son incluidas en estas mismas.

Los artículos empíricos revisados incluyeron los términos: "Teaching Arts", "Teaching Dance", "Dance Education", "College Students", "Embodiment" y "Knowledge". Los conceptos se introducen por separado y se combinan en ambas bases de datos con la opción AND. Fueron encontrados un total de 162 artículos. Se refinó la búsqueda por área: Arts and Humanities, lo cual arrojo 90 artículos. Posteriormente, se excluyeron las editoriales, revisiones de bibliografía y capítulos de libro. Además, se definió un corte temporal desde 2001 al 2016. Este último criterio, se incluyó debido a la escasez de investigaciones en esta temática particular, por lo que, este criterio permitió ampliar la búsqueda, dando un total de 34 artículos. Con la intención de aumentar la cantidad de artículos revisados asociados a Latinoamérica, se sumó la revisión de la base de datos Scielo, utilizando los mismos criterios de selección ya mencionados, a partir de los cuales fueron seleccionados 6 artículos más. Finalmente, esta revisión bibliográfica se realizó con un total de 40 artículos empíricos.

Los artículos fueron organizados en 4 categorías para su presentación, la primera de éstas se relaciona con la producción de conocimientos espacio-corporales institucionalizados en la enseñanza de la danza; la segunda categoría tiene relación con la producción de conocimientos espacio-corporales en la enseñanza de la danza en instituciones de Educación Primaria y Secundaria; la tercera categoría, considera la producción de conocimientos espacio-corporales en la enseñanza de la danza en instituciones de Educación Superior, y finalmente una cuarta categoría, que se compone por la producción de conocimientos espacio-corporales en la enseñanza de la danza en instituciones de educación no formal con población diversa.

\section{RESULTADOS}

En primera instancia, es importante señalar que, de los 40 artículos empíricos seleccionados para esta revisión, 26 artículos pertenecen a ediciones de la revista Research in Dance Education. Lo anterior da cuenta del nicho donde se está publicando la producción científica con respecto a este tema en particular.

En segunda instancia, es posible destacar que 11 artículos fueron producidos en América del Norte, 5 artículos se produjeron en América del Sur, 6 artículos fueron producidos en Oceanía, 5 artículos se produjeron en Asia, 1 artículo se produjo en África, 10 artículos 
fueron producidos en Europa y finalmente, se produjeron 2 artículos en asociación América del Norte con África, y entre dos países europeos.

En tercera instancia es importante destacar que los países donde fueron producidos estos 40 artículos se distribuyen de la siguiente forma: en América del Norte 10 artículos corresponden a EEUU, mientras que solamente 1 a Canadá; en el caso de América del Sur los 5 artículos fueron producidos en Brasil; mientras que en Oceanía se produjeron 4 artículos en Australia y 2 en Nueva Zelanda; en Asia se generaron 2 artículos en Singapur, 1 artículo en Taiwán, 1 artículo en India y finalmente, 1 artículo en Corea del Sur; el artículo que se produjo en África fue en Zimbabue; mientras que en Europa se produjeron 2 artículos en Grecia, 2 artículos en Italia, 2 artículos en España, 1 artículo en Inglaterra, 1 artículo en Noruega, 1 artículo en Hungría y 1 artículo en Suecia; los artículos en asociación se produjeron entre EEUU y Uganda, y Grecia e Inglaterra. La Figura 1 permite observar la distribución mundial de los países que en la actualidad están generando científicamente con relación a la producción de conocimientos espacio-corporales y su enseñanza en la danza.

Figura 1. Producción científica sobre conocimientos espacio-corporales a nivel mundial

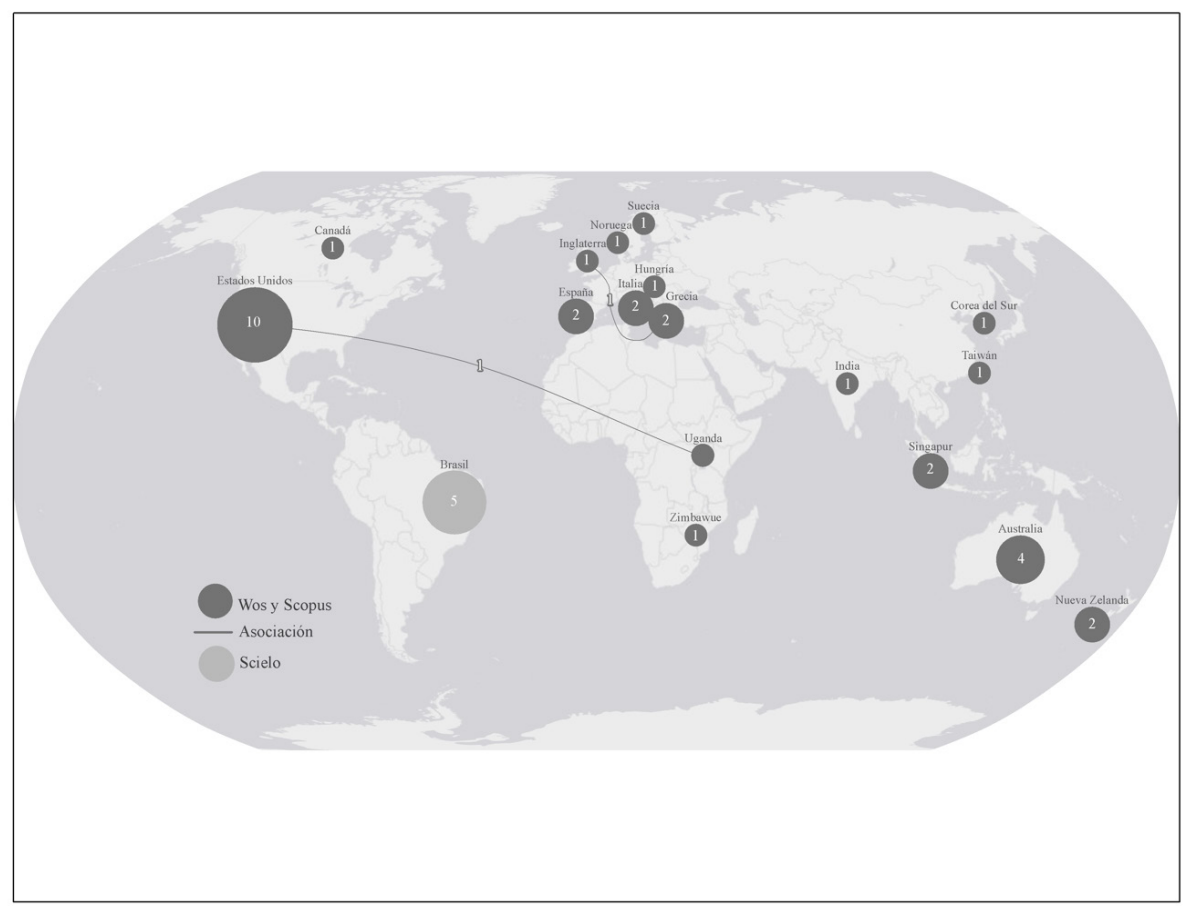

Fuente. Elaboración propia con información recopilada de las bases de datos WoS, Scopus y Scielo entre 2001 y 2016. 
A continuación, se presentarán los resultados organizados a partir de las categorías creadas para el análisis, sistematizándose y presentándose los resultados entregados por cada artículo. En primer lugar, se presentarán los resultados asociados a la categoría Producción de conocimientos espacio-corporales institucionalizados en la enseñanza de la danza.

Esta categoría es sumamente relevante, pues entrega un marco general sobre la producción de conocimientos espacio-corporales y su tratamiento en términos institucionales, desde propuestas curriculares que involucran la perspectiva de los gobiernos hasta la importancia que se les otorga en términos identitarios, lo cual también implica una postura país frente al tema.

A continuación, se presenta la Tabla 1 que compone la sistematización de los resultados.

Tabla 1. Producción de conocimientos espacio-corporales institucionalizados sobre enseñanza de la danza

\begin{tabular}{|c|c|c|c|}
\hline $\begin{array}{l}\text { Autor/es (Año) } \\
\text { Revista/País }\end{array}$ & Metodología & Objetivos & $\begin{array}{l}\text { Conocimiento espacial y } \\
\text { corporal }\end{array}$ \\
\hline $\begin{array}{l}\text { Brasileiro (2013) } \\
\text { Revista } \\
\text { Brasileira de } \\
\text { ciencia e esporte/ } \\
\text { Brasil }\end{array}$ & $\begin{array}{l}\text { Estudio } \\
\text { Cualitativo }\end{array}$ & $\begin{array}{l}\text { Conocer el significado del } \\
\text { cuerpo como instrumento y } \\
\text { objeto de estudio. }\end{array}$ & $\begin{array}{l}\text { El conocimiento corporal como } \\
\text { base para el desarrollo de la } \\
\text { enseñanza de la danza. }\end{array}$ \\
\hline $\begin{array}{l}\text { Tsompanaki } \\
\text { (2014) } \\
\text { Research in } \\
\text { Dance } \\
\text { Education/Grecia }\end{array}$ & $\begin{array}{l}\text { Estudio } \\
\text { Cualitativo }\end{array}$ & $\begin{array}{l}\text { Conocer la necesidad de } \\
\text { que la danza contemporánea } \\
\text { entre en los currículos de la } \\
\text { educación superior en } \\
\text { Grecia. }\end{array}$ & $\begin{array}{l}\text { El conocimiento corporal es } \\
\text { trabajado como conocimiento } \\
\text { técnico. }\end{array}$ \\
\hline $\begin{array}{l}\text { Stanway, Bordia } \\
\text { \& Fein (2013) } \\
\text { Arts \& } \\
\text { Humanities in } \\
\text { Higher } \\
\text { Education/ } \\
\text { Australia }\end{array}$ & $\begin{array}{l}\text { Estudio } \\
\text { Cualitativo }\end{array}$ & $\begin{array}{l}\text { Revisar lo que ofrece la } \\
\text { carrera de danza, de una } \\
\text { institución específica a los } \\
\text { interesados en ingresar a } \\
\text { estudiar. }\end{array}$ & $\begin{array}{l}\text { Instalación de un ideario sobre } \\
\text { conocimiento corporal, asociado } \\
\text { a bailarines destacados. }\end{array}$ \\
\hline $\begin{array}{l}\text { Bautista, Tan, } \\
\text { Ponnusamy \& } \\
\text { Yau (2015) } \\
\text { Journal of } \\
\text { Curriculum } \\
\text { Studies/Singapur }\end{array}$ & $\begin{array}{l}\text { Estudio } \\
\text { Cualitativo }\end{array}$ & $\begin{array}{l}\text { Conocer la implementación } \\
\text { de un currículum integrado } \\
\text { de artes. }\end{array}$ & $\begin{array}{l}\text { El conocimiento espacial es } \\
\text { trabajado, aunque de forma } \\
\text { débil y parcelada. }\end{array}$ \\
\hline $\begin{array}{l}\text { Kaktikar (2016) } \\
\text { Research in } \\
\text { Dance } \\
\text { Education/India }\end{array}$ & $\begin{array}{l}\text { Estudio } \\
\text { Cualitativo }\end{array}$ & $\begin{array}{l}\text { Demostrar que la danza } \\
\text { abhinaya tiene una caja de } \\
\text { herramientas que sirve para } \\
\text { enseñar danza en la } \\
\text { universidad. }\end{array}$ & $\begin{array}{l}\text { Esta danza supone el trabajo } \\
\text { riguroso y disciplinado del } \\
\text { cuerpo, para lograr su } \\
\text { interpretación. }\end{array}$ \\
\hline
\end{tabular}




\begin{tabular}{|c|c|c|c|}
\hline $\begin{array}{l}\text { Gonye \& Moyo } \\
\text { (2015) } \\
\text { Research in } \\
\text { Dance } \\
\text { Education/ } \\
\text { Zimbabue }\end{array}$ & $\begin{array}{l}\text { Estudio } \\
\text { Mixto }\end{array}$ & $\begin{array}{l}\text { Rescatar la apuesta } \\
\text { pedagógica que permite } \\
\text { comprender la tradición y la } \\
\text { herencia de este tipo de } \\
\text { conocimiento. }\end{array}$ & $\begin{array}{l}\text { El conocimiento corporal y } \\
\text { espacial es manejado por los } \\
\text { profesores, quienes a su vez } \\
\text { tienen un conocimiento acabado } \\
\text { sobre danzas tradicionales. }\end{array}$ \\
\hline $\begin{array}{l}\text { Tsompanaki \& } \\
\text { Benn (2011) } \\
\text { Research in } \\
\text { Dance } \\
\text { Education/ } \\
\text { Grecia- } \\
\text { Inglaterra }\end{array}$ & $\begin{array}{l}\text { Estudio } \\
\text { Cualitativo }\end{array}$ & $\begin{array}{l}\text { Explorar las similitudes y } \\
\text { diferencias entre los } \\
\text { sistemas educacionales de } \\
\text { danza de tercer nivel de } \\
\text { Grecia e Inglaterra para } \\
\text { mejorar su comprensión. }\end{array}$ & $\begin{array}{l}\text { El conocimiento corporal y } \\
\text { espacial en Inglaterra es } \\
\text { trabajado desde lo teórico y lo } \\
\text { práctico. En el caso Griego el } \\
\text { conocimiento corporal, es } \\
\text { técnico. }\end{array}$ \\
\hline
\end{tabular}

La Tabla 1 identifica a los autores, el año, la revista, el país, el tipo de metodología que fue utilizada en la investigación, el objetivo general de la investigación, y la apuesta de producción de conocimiento espacio-corporal que se está postulando.

Según el estudio realizado por Tsompanaki \& Benn (2011), la enseñanza de la danza en Grecia e Inglaterra se diferencian, de la siguiente manera: en Inglaterra la enseñanza de la danza se da en la Universidad, mientras que en Grecia no es así -si se intenta equiparar la realidad de ambos países- los estudios del tipo college inglés serían lo más similar, es decir, estudios vocacionales sin grado. El enfoque de este artículo se centra en las experiencias y percepciones de los alumnos. Los estudiantes ingleses se muestran satisfechos con la estructura, contexto y medios que les proveen sus instituciones y son optimistas respecto al futuro. Sienten que la experiencia los está transformando como individuos; ello se debe a que se les entrena como a bailarines conceptuales y practicantes pensantes, abordando el conocimiento espacial y corporal ampliamente. En el caso griego, los estudiantes admiten que su educación y entrenamiento tiene un enfoque más "transmisivo", en donde se pone el énfasis en valores más instrumentales, formándose entonces, bailarines técnicos. Su individualidad se ve obstaculizada creándose un ambiente muy competitivo en el aula. La mayoría de los participantes griegos muestran descontento con los cursos, pues el conocimiento que manejan es solamente profesionalizante.

Tsompanaki (2014), también profundiza en la idea de incluir la danza en la formación superior pública en Grecia, las instituciones que si imparten danza son todas del ámbito privado. De esta forma, se intentó explorar en el status de la danza en la educación superior griega a través de un estudio de caso a 3 de las 6 instituciones que imparten danza en Grecia, considerando la experiencia de estudiantes, docentes, coordinadores de curso y de la investigadora. Los resultados demuestran nuevamente que la educación y el entrenamiento de la danza en Grecia proveen de un enfoque "transmisivo", lo que da por resultado, la preponderancia de los tecnicismos dancísticos.

En el caso de Brasil, el artículo de Brasileiro (2013) presenta solamente el análisis documental de la investigación desarrollada, donde se revisan 2 propuestas curriculares de instituciones de educación superior: Universidad Federal de Bahía (UFBA) y Universidad Estadual de Campinas (UNICAMP). Definiéndose, que el conocimiento corporal es central en la formación dancística, en ambas instituciones. Esto instala un requerimiento primordial, 
la necesidad imperante de abordar este conocimiento desde una perspectiva teórica y una perspectiva práctica.

En Australia, el estudio de Stanway, Bordia \& Fein (2013), plantea que las instituciones de formación superior en danza desarrollan una apuesta para promocionar sus carreras, incluyendo a bailarines destacados que egresaron de su institución, por tanto, quienes ingresan a esa institución asumen que su desarrollo corporal debiese seguir el modelo del bailarín destacado.

Bautista, Tan, Ponnusamy \& Yau (2015), proponen el trabajo con el currículum de artes integradas, según su investigación el conocimiento que se produce es débil, sin embargo, el conocimiento espacial es el más trabajado. En este sentido, se realiza una declaración por parte de los investigadores, quienes apuestan por el trabajo interdisciplinar y en apoyo con especialistas desde las diversas áreas. De esta forma, el estudio da cuenta de que no es posible lograr integración si el conocimiento pedagógico se aleja del conocimiento disciplinar.

Finalmente, otro de los elementos macroestructurantes son las danzas tradicionales que muchas veces son parte del currículum escolar, pues refuerzan aspectos nacionales e identitarios. En el caso de la investigación realizada por Kaktikar (2016), los resultados demostraron que una danza tradicional puede tener impacto en los estudiantes, pues entrega rigurosidad y disciplina. Además, es importante que sea un curso con créditos, donde los estudiantes deben cumplir obligatoriamente con su asistencia y finalización. Este tipo de danza demuestra el poder tradicional de una cultura, permite ir más allá de una visión tradicional e incluso plantear una propuesta anti-colonialista.

Gonye \& Moyo (2015), también examinan la enseñanza de la danza tradicional, aunque en este caso en Zimbabue, considerando el paradigma indigenista postcolonialista. En este paper se rescatan 15 danzas tradicionales, las cuales surgieron en los focus group con docentes. En las encuestas se les pregunto directamente por un tipo de danza y su propósito, hubo un alto porcentaje de profesores que sabía cabalmente el objetivo de la danza. Esto implica, manejo del conocimiento práctico y de ejecución, y el conocimiento teórico que permite dar vida al relato que se expresa en esa danza.

Es importante destacar que, de las siete investigaciones aquí presentadas, solamente tres hacen referencia a la producción de conocimiento espacial, y una de las tres da cuenta de que la apuesta curricular que se presenta, dicotomiza y parcela el conocimiento. Mientras que la investigación de carácter comparativo; evidencia el interés por trabajar la producción de un conocimiento espacio-corporal en la formación dancística inglesa. Siendo la formación dancística griega más desarrollada en la ejecución y la técnica. Las cuatro investigaciones restantes consideran relevante la producción del conocimiento corporal sobretodo en relación a la ejecución del movimiento y de la interpretación, siendo fundamental el desarrollo corporal del bailarín, en términos de resistencia y adquisición de conciencia y memoria corporal.

Esta revisión crítica de literatura propone como segunda categoría de análisis y sistematización la Producción de conocimientos espacio-corporales en la enseñanza de la danza en instituciones de Educación Primaria y Secundaria. Se considera, que luego de realizar una revisión macro-estructural de la producción de los conocimientos espaciocorporales a nivel de propuestas estatales que se traducen en el ámbito curricular, es relevante revisar como estas propuestas se incluyen o no, en la formación escolar.

A continuación, se presenta la Tabla 2, que responde a la segunda categoría ya mencionada. 
Tabla 2. Producción de conocimientos espacio-corporales en la enseñanza de la danza en instituciones de Educación Primaria y Secundaria

\begin{tabular}{|c|c|c|c|}
\hline Autor/es (Año) & Metodología & Objetivos & $\begin{array}{l}\text { Conocimiento espacial y } \\
\text { corporal }\end{array}$ \\
\hline $\begin{array}{l}\text { Spagnuolo \& Colket } \\
\text { (2016) } \\
\text { Research in Dance } \\
\text { Education/EEUU }\end{array}$ & $\begin{array}{l}\text { Estudio } \\
\text { Cualitativo }\end{array}$ & $\begin{array}{l}\text { Reconocer el impacto de } \\
\text { las clases de un profesor de } \\
\text { danza que está realizando } \\
\text { su práctica de magíster en } \\
\text { una sala de aula escolar. }\end{array}$ & $\begin{array}{l}\text { El conocimiento corporal es } \\
\text { trabajado por medio de } \\
\text { metáforas, y no por medio de } \\
\text { conocimiento anatómico. }\end{array}$ \\
\hline $\begin{array}{l}\text { Russell-Bowie (2013) } \\
\text { Research in Dance } \\
\text { Education/Australia }\end{array}$ & $\begin{array}{l}\text { Estudio } \\
\text { cuantitativo }\end{array}$ & $\begin{array}{l}\text { Identificar las percepciones } \\
\text { de profesores de primaria, } \\
\text { en cuanto a su conocimiento } \\
\text { de enseñanza de la danza, } \\
\text { en relación a su bagaje, } \\
\text { edad y país de origen. }\end{array}$ & $\begin{array}{l}\text { El conocimiento espacial y } \\
\text { corporal es débil. }\end{array}$ \\
\hline $\begin{array}{l}\text { Shue \& Beck (2001) } \\
\text { C o m m u n i c a t i o n } \\
\text { Education/EEUU }\end{array}$ & $\begin{array}{l}\text { Estudio } \\
\text { Cualitativo. } \\
\text { Etnografía } \\
\text { crítica. }\end{array}$ & $\begin{array}{l}\text { Demostrar como la cultura } \\
\text { pedagógica declarada en la } \\
\text { enseñanza de la danza, no } \\
\text { se relaciona con la práctica. }\end{array}$ & $\begin{array}{l}\text { No se desarrolla el } \\
\text { conocimiento espacial ni } \\
\text { corporal. La competencia es } \\
\text { la que se fortalece para } \\
\text { producir aprendizaje. }\end{array}$ \\
\hline $\begin{array}{l}\text { Lum \& Gonda (2014) } \\
\text { Research in Dance } \\
\text { Education/Singapur }\end{array}$ & $\begin{array}{l}\text { Estudio } \\
\text { Cualitativo. } \\
\text { Estudio de } \\
\text { caso. }\end{array}$ & $\begin{array}{l}\text { Examinar las pedagogías y } \\
\text { prácticas de un maestro de } \\
\text { danza Bharata Natyam, } \\
\text { trabajando en el contexto } \\
\text { de un colegio primario de } \\
\text { Singapur. }\end{array}$ & $\begin{array}{l}\text { Este tipo de danza posee todo } \\
\text { un bagaje y conocimientos } \\
\text { que deben ser desarrollados. }\end{array}$ \\
\hline $\begin{array}{l}\text { Andrada \& } \text { Souza } \\
(2015) \\
\text { Revista } \\
\text { da }\end{array}$ & $\begin{array}{l}\text { Estudio } \\
\text { Cualitativo }\end{array}$ & $\begin{array}{l}\text { Analizar el potencial de la } \\
\text { danza circular, como } \\
\text { movilizadora de afectos. }\end{array}$ & $\begin{array}{l}\text { Se trabaja el conocimiento } \\
\text { corporal, pero presenta la } \\
\text { urgencia en desarrollar el } \\
\text { conocimiento espacial. }\end{array}$ \\
\hline $\begin{array}{l}\text { Tai (2014) } \\
\text { Research in Dance } \\
\text { Education/Taiwan }\end{array}$ & $\begin{array}{l}\text { Estudio } \\
\text { Cualitativo }\end{array}$ & $\begin{array}{l}\text { Efectos que poseen en un } \\
\text { estudiante de danza, la } \\
\text { participación en el concurso } \\
\text { nacional de danza. }\end{array}$ & $\begin{array}{l}\text { Los estudiantes imitan las } \\
\text { aptitudes de los profesores, de } \\
\text { esta forma el conocimiento } \\
\text { corporal es trabajado a partir } \\
\text { de la imitación. }\end{array}$ \\
\hline $\begin{array}{l}\text { Sims, Abel, Clasey, } \\
\text { Beighle, Fedewa \& } \\
\text { Erwin (2016) } \\
\text { Research in Dance } \\
\text { Education/EEUU }\end{array}$ & \begin{tabular}{|l|} 
Estudio \\
Cuantitativo \\
\end{tabular} & $\begin{array}{l}\text { Demostrar los beneficios de } \\
\text { la danza en términos de } \\
\text { acondicionamiento físico. }\end{array}$ & $\begin{array}{l}\text { La observación es } \\
\text { fundamental para comprender } \\
\text { las capacidades corporales. }\end{array}$ \\
\hline $\begin{array}{l}\text { Miranda \& } \quad \text { Cury } \\
\text { (2010) } \\
\text { Paidéia/Brasil }\end{array}$ & $\begin{array}{l}\text { Estudio } \\
\text { Cualitativo. } \\
\text { Narrativas. }\end{array}$ & $\begin{array}{lcr}\text { Comprender } & \text { el } & \text { desarrollo } \\
\text { psicológico } & \text { de } & \text { los } \\
\text { estudiantes } & \text { en } & \text { la } \\
\text { experiencia dancística. } & \end{array}$ & $\begin{array}{l}\text { El conocimiento corporal se } \\
\text { desarrolla por medio de la } \\
\text { práctica de la danza. }\end{array}$ \\
\hline
\end{tabular}


Es relevante destacar que los artículos presentados en la tabla 2, incluyen realidades distintas a las presentadas en la tabla 1. Se incluyen investigaciones realizadas en EEUU, Singapur y Taiwán, lo que da cuenta del desarrollo de la disciplina en estos países, y de una discusión instalada sobre producción de conocimiento espacio-corporal.

En el estudio de Spagnuolo \& Colket (2016) se destacan los resultados asociados al impacto de los momentos de descanso durante el aprendizaje del movimiento, estos espacios temporales permiten la asimilación corporal. Los estudiantes avanzados utilizan estos momentos en que se pueden estirar, conocer y sentir sus cuerpos, para asimilar y memorizar el movimiento. En el caso de los estudiantes principiantes, el descanso es menor pues están recién comenzando su trabajo en la técnica académica. Otro de los elementos importantes es el imaginario que se tiene del cuerpo. Los profesores de danza enseñan las coreografías con metáforas, pero según lo recopilado en esta investigación, un mayor impacto se lograría al vincular lo metafórico con conocimiento anatómico e incluso con terminología médica, esto logra que el estudiante reconozca las partes de su propio cuerpo.

Miranda \& Cury (2010) en su estudio, postulan que la práctica de la danza en adolescentes fortalece sus capacidades y comprensión de su propio cuerpo. Es la danza hip hop con toda su carga política, la que permite que los estudiantes, se involucren con los aprendizajes corporales que van desarrollando, al mismo tiempo van generando una comprensión sobre su propio territorio. De la misma forma, en el estudio de Andrada \& Souza (2015), se considera fundamental la afectividad en la enseñanza de la danza, es el docente el que debe preocuparse por trabajar con este elemento. De esta manera, los estudiantes suponen un trabajo dedicado para aprender sobre su cuerpo, sin embargo, en este estudio se evidencia que el trabajo con el conocimiento espacial ha sido desplazado y se hace un llamado a la urgencia que tiene su incorporación en la enseñanza de la danza.

En el caso del estudio cuantitativo de Sims, Abel, Clasey, Beighle, Fedewa \& Erwin (2016), la observación es relevante para el entrenamiento y ejecución de los bailarines, ya que provee de un sistema que determina los niveles de actividad física que los bailarines exhiben durante una clase. Estos niveles de acondicionamiento físico indudablemente realizan un aporte a la comprensión corporal, debido a las posturas que deben trabajar, pero también en relación a otro cuerpo, ya que deben comprender cuál es el volumen del cuerpo en el espacio.

Tai (2014), también plantea que la influencia del profesor en el estudiante es importante, y permea la identidad del bailarín. Esto supone, que existen rasgos dancísticos que son propios del instructor y que el estudiante aprende, pues es exigido para esto. La investigación se centra en una competencia en Taiwán que era promovida por el ministerio de defensa, pero en el año 2001 pasa a ser parte del Ministerio de Educación, por tanto, el entrenamiento es paralelo a la escuela y su duración es por todos los años de escolaridad. La danza es utilizada como artefacto cultural y para la formación de campeones.

Desde una perspectiva similar, Shue \& Beck (2001) plantean que los profesores que enseñan danza en base a la competencia están constantemente diciéndole a los estudiantes cuáles son sus debilidades y errores. Esto coarta la libertad de expresión de los estudiantes. Según el estudio, hay dos elementos que promueven este tipo de enseñanza, por una parte, la forma tradicional de enseñanza arraigada en las docentes y por otra parte, el modelo comercial en que los apoderados pagan para un mejor entrenamiento, lo cual se traduce en campeonatos ganados. 
Russell-Bowie (2013), investigaron sobre el bagaje dancístico que poseen los profesores de danza. Siendo los docentes de África del Sur y Namibia, quienes poseen mayor conocimiento de la danza de sus territorios, esto porque la danza es parte de la cultura de estas sociedades, de su historia. Asimismo, las mujeres se destacaban por sobre los hombres, en cuanto al conocimiento de mayor cantidad de danzas.

En el estudio de Lum \& Gonda (2014), también se trabajan las tradiciones que pueden ser transmitidas por medio de una danza tradicional, los temas que emergieron de los datos recolectados hablan mayoritariamente de cómo han cambiado las tradiciones y prácticas del Bharata Natyan, incluyendo la relación guru-shishya y el proceso de enseñanza y la selección del repertorio de la danza para adaptarla a un ambiente escolar laico.

Las investigaciones aquí presentadas demuestran que, en el ámbito escolar, se mantiene el predominio de una enseñanza por imitación kinética, lo que permite que el estudiante replique el movimiento que es presentado por los profesores, sin que exista un cuestionamiento al respecto. Esta visión tradicional da cuenta de cómo las apuestas curriculares, que son teóricamente innovadoras en la práctica toman otro rumbo. Asimismo, es importante considerar que se introduce un tema que no fue visualizado en la apuesta institucionalizada, que es la inclusión del modelo clientelista en educación, los padres pagan para que sus hijos aprendan ciertos elementos técnicos de la ejecución dancística. Esto supone una comprensión de la producción del conocimiento espacio-corporal enfocado en la meta, y que se encuentra presente mayoritariamente en las investigaciones realizadas en EE.UU.

Como tercera categoría de análisis propuesta para esta revisión, se considera relevante identificar cómo se produce conocimiento espacio-corporal en las instituciones de Educación Superior, pues la distancia entre las enseñanzas en el ámbito escolar y el pregrado, siempre han supuesto ciertos vacíos y desencuentros, sin importar la disciplina que se esté trabajando.

Tabla 3. Producción de conocimientos espacio-corporales en la enseñanza de la danza en instituciones de Educación Superior

\begin{tabular}{|c|c|c|c|}
\hline Autor/es & Metodología & Objetivos & Conocimiento espacial y corporal \\
\hline $\begin{array}{l}\text { Pulinkala (2011) } \\
\text { Research in Dance } \\
\text { Education/ EEUU }\end{array}$ & $\begin{array}{l}\text { Estudio } \\
\text { Cualitativo. } \\
\text { Estudio de } \\
\text { caso. }\end{array}$ & $\begin{array}{l}\text { Beneficios en la formación } \\
\text { inicial de alianzas entre } \\
\text { compañías e instituciones de } \\
\text { educación superior. }\end{array}$ & $\begin{array}{l}\text { Predominancia del aprendizaje } \\
\text { espacial y corporal, trabajado por } \\
\text { la compañía de danza. }\end{array}$ \\
\hline $\begin{array}{l}\text { Huddy \& Stevens } \\
\text { (2011) } \\
\text { Research in Dance } \\
\text { Education/ } \\
\text { Australia }\end{array}$ & $\begin{array}{l}\text { Estudio } \\
\text { Cualitativo }\end{array}$ & $\begin{array}{l}\text { La profesión } \\
\text { centrada en la práctica } \\
\text { artística. }\end{array}$ & $\begin{array}{l}\text { Los profesores de danza, deben } \\
\text { ser coreógrafos e intérpretes, } \\
\text { solamente de esta forma pueden } \\
\text { enseñar el conocimiento espacial } \\
\text { y corporal. }\end{array}$ \\
\hline $\begin{array}{l}\text { Pastore \& } \\
\text { Pentasussuglia } \\
\text { (2014) } \\
\text { International } \\
\text { Journal of Educatio } \\
\text { Research/Italia }\end{array}$ & $\begin{array}{l}\text { Estudio } \\
\text { Cualitativo. } \\
\text { Estudio de } \\
\text { caso. }\end{array}$ & $\begin{array}{l}\text { Develar las prácticas de los } \\
\text { profesores de danza, cuando } \\
\text { esas prácticas son } \\
\text { performáticas. }\end{array}$ & $\begin{array}{l}\text { El conocimiento corporal se basa } \\
\text { en un supuesto epistemológico, } \\
\text { las técnicas corporales son } \\
\text { trabajadas con mayor facilidad, } \\
\text { ya que son incorporadas en la } \\
\text { memoria corporal. }\end{array}$ \\
\hline
\end{tabular}




\begin{tabular}{|c|c|c|c|}
\hline $\begin{array}{l}\text { Risner \& } \\
\text { Anderson (2015) } \\
\text { Teaching Artist } \\
\text { Journal/EEUU }\end{array}$ & $\begin{array}{l}\text { Estudio } \\
\text { Cualitativo }\end{array}$ & $\begin{array}{l}\text { Identificar las necesidades } \\
\text { de los profesores de artes } \\
\text { que están en un programa } \\
\text { diseñado para profesores de } \\
\text { artes en danza y teatro. }\end{array}$ & $\begin{array}{l}\text { Se establece la necesidad de } \\
\text { trabajar más métodos } \\
\text { pedagógicos de enseñanza, que } \\
\text { métodos relacionados con el } \\
\text { conocimiento espacial y corporal. }\end{array}$ \\
\hline $\begin{array}{l}\text { Englund \& } \\
\text { Sandstrom } \\
(2015) \\
\text { Research in Dance } \\
\text { Education/Suecia }\end{array}$ & $\begin{array}{l}\text { Estudio } \\
\text { Cualitativo }\end{array}$ & \begin{tabular}{lll}
\multicolumn{2}{l}{ Examinar la expresión } \\
verbal de & profesores de \\
danza, en & situaciones de \\
enseñanza. &
\end{tabular} & $\begin{array}{l}\text { Los conocimientos espaciales y } \\
\text { corporales son comunicados } \\
\text { verbalmente por medio de } \\
\text { metáforas. }\end{array}$ \\
\hline $\begin{array}{l}\text { García-Dantas, } \\
\text { Caracuel-Tubío \& } \\
\text { Peñaloza-Gómez } \\
\text { (2012) } \\
\text { Cuadernos de } \\
\text { Psicología del } \\
\text { Deporte/España }\end{array}$ & $\begin{array}{l}\text { Estudio } \\
\text { Cuantitativo }\end{array}$ & $\begin{array}{l}\text { Controlar el impacto del } \\
\text { castigo en la enseñanza de la } \\
\text { danza. }\end{array}$ & $\begin{array}{l}\text { El castigo es utilizado } \\
\text { comúnmente en la enseñanza de } \\
\text { la danza, y esto genera un } \\
\text { rechazo por el conocimiento en } \\
\text { general. }\end{array}$ \\
\hline $\begin{array}{l}\text { Biasutti (2013) } \\
\text { Research in Dance } \\
\text { Education/Italia }\end{array}$ & \begin{tabular}{|l} 
Estudio \\
Cualitativo, \\
Grounded \\
theory para \\
analizar los \\
datos. \\
\end{tabular} & $\begin{array}{l}\text { Establecer la importancia de } \\
\text { usar la improvisación en la } \\
\text { enseñanza de la danza. }\end{array}$ & $\begin{array}{l}\text { Se establece una relación con el } \\
\text { cuerpo de libertad, las } \\
\text { sensaciones corporales son } \\
\text { incorporadas en la enseñanza. }\end{array}$ \\
\hline $\begin{array}{l}\text { go (2015) } \\
\text { ch in Dance } \\
\text { tion/EEUU- } \\
\text { a }\end{array}$ & $\begin{array}{l}\text { Estudio } \\
\text { Cualitativo }\end{array}$ & $\begin{array}{l}\text { Examinar como toda la } \\
\text { experiencia de estudio en el } \\
\text { extranjero se ha integrado en } \\
\text { el trabajo posterior de los } \\
\text { profesores de danza. }\end{array}$ & $\begin{array}{l}\text { Incorporaron los aprendizajes } \\
\text { asociados al espacio y al cuerpo, } \\
\text { en su trabajo como formadores. }\end{array}$ \\
\hline $\begin{array}{l}\text { Roche \& Huddy } \\
\text { (2015) } \\
\text { Theatre, Dance } \\
\text { and Performance } \\
\text { Training/Australia }\end{array}$ & $\begin{array}{l}\text { Estudio } \\
\text { Mixto }\end{array}$ & $\begin{array}{l}\text { Impacto de los estilos de } \\
\text { enseñanza tradicional de la } \\
\text { danza. }\end{array}$ & $\begin{array}{l}\text { El aprendizaje debiese ser } \\
\text { holístico. }\end{array}$ \\
\hline $\begin{array}{l}\text { Banerjee (2013) } \\
\text { Research in Dance } \\
\text { Education/EEUU }\end{array}$ & $\begin{array}{l}\text { Estudio } \\
\text { Cualitativo }\end{array}$ & $\begin{array}{l}\text { Observar cómo los alumnos } \\
\text { de pregrado en universidades } \\
\text { norteamericanas entienden y } \\
\text { reciben una práctica cultural } \\
\text { particular (para el caso, } \\
\text { Bharatanatyam } \\
\text { pedagogy). }\end{array}$ & $\begin{array}{l}\text { Se cuestiona la transmisión de } \\
\text { conocimiento lineal del profesor } \\
\text { hacia el estudiante. }\end{array}$ \\
\hline $\begin{array}{l}\text { Torrents, Castañer, } \\
\text { Dinusová \& } \\
\text { Anguera } \\
\text { (2013) } \\
\text { Research in Dance } \\
\text { Education/España }\end{array}$ & $\begin{array}{l}\text { Estudio } \\
\text { Mixto }\end{array}$ & $\begin{array}{l}\text { Analizar la construcción } \\
\text { utilizada por los profesores } \\
\text {-descriptiva, metafórica o con } \\
\text { modelo- que ayuda a generar } \\
\text { acciones motoras (o motrices) } \\
\text { más divergentes. }\end{array}$ & $\begin{array}{l}\text { El conocimiento corporal y } \\
\text { espacial es mayormente } \\
\text { aprendido, cuando las estrategias } \\
\text { del profesor son más variadas. }\end{array}$ \\
\hline $\begin{array}{l}\text { Scarpato (2001) } \\
\text { Cadernos Cedes/ } \\
\text { Brasil }\end{array}$ & $\begin{array}{l}\text { Estudio } \\
\text { Cualitativo }\end{array}$ & $\begin{array}{l}\text { Demostrar que el curso de } \\
\text { danza educativa de la PUC- } \\
\text { Paulista sirve para enseñar } \\
\text { la relación mente-cuerpo. }\end{array}$ & $\begin{array}{l}\text { La técnica académica no } \\
\text { motivaría el aprendizaje del } \\
\text { conocimiento corporal. }\end{array}$ \\
\hline
\end{tabular}


En la Tabla 3 se revisan 12 artículos, esto da cuenta de una mayor discusión sobre la enseñanza de la danza en la educación superior, que en las categorías anteriormente presentadas. Son estos espacios los que, mantienen la vanguardia en relación a la producción de los conocimientos.

En primer lugar, es importante considerar que existen elementos disciplinares muy fuertes en la enseñanza de la danza, según Scarpato (2001) la danza educativa debiese ser una modalidad a trabajarse en la educación superior, ya que la persistencia de los elementos de repetición e imitación en la técnica académica, no motiva el aprendizaje real del conocimiento corporal, mucho menos del conocimiento espacial, ya que el danzante debe mantenerse lo más alejado del suelo posible, solamente la punta de sus pies pueden estar en contacto con él. Es importante, además, considerar los elementos punitivos durante la enseñanza de esta técnica, García-Dantas, Caracuel-Tubío \& Peñaloza-Gómez (2012) realizaron una investigación cuantitativa con 5 profesores de danza, quienes fueron sometidos al Coaching Behavior Assesmente (CBAS) ${ }^{1}$ para que aquellas enseñanzas que transmitían por medio de castigos o refuerzos negativos ya no fueran enseñadas de esta forma. Es importante destacar como las motivaciones de los estudiantes tienen relación con las formas de enseñanza, en este caso específico se comprobó que, a mayor acompañamiento y afectividad, los aprendizajes eran más significativos.

Banerjee (2013), en su estudio se centra en como el profesor de danza genera una pedagogía adaptativa, sensible a los intereses y necesidades de quien está aprendiendo en convivencia con sus capacidades e inclinaciones culturales. También demuestra la necesidad de crear espacios críticos para el diálogo. Como base de esta perspectiva, hay una preocupación por cuestionar la forma lineal en la que el conocimiento es transmitido de maestro a estudiante. Se propone que el conocimiento necesita ser construido y contestado a la luz de las actitudes culturales, las motivaciones y las disposiciones de los estudiantes. Torrents, Castañer, Dinusová \& Anguera (2013), en su estudio mixto plantean que los estudiantes intentan generar respuestas motoras propias, pero copian componentes fundamentales del modelo del profesor; las instrucciones metafóricas y descriptivas parecen estimular la creatividad motora, generando respuestas más variadas. En este sentido, al utilizar los tres tipos de instrucciones que ellos investigaron ocurren mayores variaciones en las respuestas de los estudiantes en las categorías de tiempo, cuerpo, postura y gestualidad.

En el segundo estudio mixto de esta categoría de Roche \& Huddy (2015), se señala que los estilos de aprendizaje necesitan del desarrollo de un enfoque holístico dirigido a la cultura de la enseñanza-aprendizaje, dentro del departamento de danza de la Queensland University of Technology (QUT). Con el fin de llevarlo a cabo, el equipo necesitará apoyo constante para el desarrollo profesional. Los resultados del estudio piloto fueron abrumadoramente positivos y apoyaron la continuidad de investigaciones acerca del método Feldenkrais y otros enfoques de danza en las clases técnicas de danza del QUT.

Pastore \& Pentasussuglia (2014), incorporan un nuevo elemento en el análisis y este es que la profesora de danza tiene una posición epistemológica sobre cuerpo y cómo trabajarlo. En este caso, se establece que uno de los elementos que dificultaron la comprensión de los resultados, fue que solamente se observaron clases de 60 minutos, pero el desarrollo

Solamente 3 profesores aprendieron el sistema, por tanto, compusieron el grupo de control. Mientras que los otros 2 profesores, no fueron parte del CBAS. 
profesional como bailarina de la propia profesora, no fue observado. En este análisis no se consideran las habilidades, destrezas y tecnicismos que los cuerpos ya han logrado. Entonces, la relación entre las prácticas performáticas de la profesora y su trabajo en el aula, no se pueden ver a largo plazo. Aunque, si se puede identificar lo especifico de sus prácticas.

Englund \& Sandstrom (2015), por su parte plantean que los resultados de su estudio demuestran que los conocimientos respecto a los valores expresivos del movimiento son comunicados verbalmente hasta cierto punto, pero esta comunicación de los mismos es vaga y transmitida de una forma que hace que la interpretación de los estudiantes novatos sea muy dificultosa. De forma alternativa, se utiliza lenguaje metafórico, así como modelos no verbales de comunicación para desarrollar el conocimiento espacial y corporal.

Biasutti (2013), realiza un análisis según las metodologías que se utilizan en la enseñanza de la danza, los resultados exponen la emergencia de subcategorías: espontaneidad, emoción, sensación corporal, y libertad. En cuanto a la segunda apreciación metodológica, existe un uso de la técnica de forma personal, desapego con el espacio-tiempo, y experimentación con movimientos originales. Asimismo, se plantea la improvisación como una de las metodologías más importantes para trabajar la enseñanza de la danza. Según Mabingo (2015), las motivaciones de los estudiantes superan las metodologías, pues sus resultados, demuestran que los sujetos participantes integran las experiencias aprendidas en el exterior (Uganda) a su trabajo profesional en áreas tales como su filosofía profesional, objetivos profesionales, comprensión del ambiente de trabajo, pedagogía que usan al enseñar, currículo y clases que desarrollan para guiar su enseñanza, formas de evaluación, formas de retroalimentación, relaciones maestro-estudiante, manejo de la clase y estrategias de evaluación de su propio desempeño como educadores. En este sentido se vuelve relevante el trabajo pedagógico. En esta misma línea Risner \& Anderson (2015), obtuvieron en sus resultados que los participantes declararon, que era necesario reforzar la parte pedagógica en los programas universitarios de artes, además de aprender métodos de enseñanza pedagógica.

Huddy \& Stevens (2011), plantean que es importante mantener vínculos entre los profesores de danza en formación y las escuelas. Además, es importante consolidar una formación de pedagogos en danza, que contemple el ámbito artístico y académico. Plantean que los profesores de danza deben ser investigadores, coreógrafos y bailarines, para poder enseñar en las escuelas. Pulinkala (2011) aporta en esta línea, pues menciona que las relaciones entre bailarines activos (intérpretes y coreógrafos) y profesores de danza (bailarines retirados), son importantes para que los elementos espaciales puedan ser bien enseñados, en este sentido, la formación dancística debería considerar trabajar con la vinculación profesional, como forma de que el conocimiento espacial sea trabajado adecuadamente.

Las investigaciones aquí presentadas, relevan la importancia de la revisión de la práctica dancística desde sus fundamentos pedagógicos. Esto permite que en su mayoría realicen un cuestionamiento de las prácticas de enseñanza tradicionales e incluso de sus propios supuestos epistemológicos que son sostenedores de estas prácticas. Lo anterior, repercute directamente en la producción de conocimiento espacio-corporal, pues existe una preocupación constante por no trabajar dicotómicamente la producción de este conocimiento, y por no caer en prácticas punitivas que valoren solamente la ejecución del movimiento. 
Como última categoría de análisis propuesta para esta revisión, se encuentra la Producción de conocimientos espacio-corporales en la enseñanza de la danza en instituciones de educación no formal con población diversa. Esta categoría surge porque justamente son los espacios que no están institucionalizados, los que demuestran en ocasiones mayor rapidez en la permeabilidad de aquellas propuestas que surgen en la Educación Superior o por el contrario, son los nichos donde surgen las nuevas propuestas.

Tabla 4. Producción de conocimientos espacio-corporales en la enseñanza de la danza en instituciones de educación no formal con población diversa

\begin{tabular}{|c|c|c|c|}
\hline Autor/es (Año) & Metodología & Objetivos & $\begin{array}{l}\text { Conocimiento espacial y } \\
\text { corporal }\end{array}$ \\
\hline $\begin{array}{l}\text { Koff \& Mistry } \\
(2012) \\
\text { Research in } \\
\text { Dance Education/ } \\
\text { EEUU }\end{array}$ & $\begin{array}{l}\text { Estudio } \\
\text { Cualitativo }\end{array}$ & $\begin{array}{l}\text { Trabajar el tema del } \\
\text { profesionalismo en la enseñanza } \\
\text { de la danza, en la comunidad de } \\
\text { Nueva Orleans, luego del } \\
\text { huracán Katrina. }\end{array}$ & $\begin{array}{l}\text { La identidad profesional se } \\
\text { funda en el conocimiento } \\
\text { disciplinar que poseen, pero } \\
\text { además en las condiciones } \\
\text { laborales. }\end{array}$ \\
\hline $\begin{array}{l}\text { Tsouvala \& } \\
\text { Magos (2016) } \\
\text { Research in } \\
\text { Dance Education/ } \\
\text { Grecia }\end{array}$ & $\begin{array}{l}\text { Estudio } \\
\text { Cualitativo }\end{array}$ & $\begin{array}{l}\text { Descubrir si los participantes del } \\
\text { proyecto de danza pueden evaluar } \\
\text { y reformular sus concepciones } \\
\text { sobre sus cuerpos y espacio. }\end{array}$ & $\begin{array}{l}\text { Se comprende } \\
\text { heterogeneidad de los cuerpos } \\
\text { y, por tanto, la producción de } \\
\text { nuevos espacios. }\end{array}$ \\
\hline $\begin{array}{l}\text { Watson, Nordin- } \\
\text { Bates \& Chappell } \\
\text { (2012) } \\
\text { Research in } \\
\text { Dance Education/ } \\
\text { Inglaterra }\end{array}$ & $\begin{array}{l}\text { Estudio } \\
\text { Cualitativo }\end{array}$ & $\begin{array}{l}\text { Establecer que los métodos de } \\
\text { enseñanza que se están } \\
\text { utilizando no trabajan los } \\
\text { aspectos creativos, sino que más } \\
\text { bien solamente los aspectos } \\
\text { técnicos. }\end{array}$ & $\begin{array}{l}\text { El conocimiento corporal } \\
\text { radica en el aprendizaje técnico } \\
\text { del cuerpo, su funcionamiento } \\
\text { anatómico. }\end{array}$ \\
\hline $\begin{array}{l}\text { Testa (2012) } \\
\text { Interface } \\
\text { comunicacao, } \\
\text { saude e educacao/ } \\
\text { Brasil }\end{array}$ & $\begin{array}{l}\text { Estudio } \\
\text { Cualitativo }\end{array}$ & $\begin{array}{l}\text { Reconocer las formas en que el } \\
\text { cuerpo responde a una } \\
\text { institución psiquiátrica. }\end{array}$ & $\begin{array}{l}\text { El conocimiento espacial y } \\
\text { corporal se desarrolla por } \\
\text { medio de la práctica dancística, } \\
\text { esto permite que los internos se } \\
\text { hagan conscientes de estos. }\end{array}$ \\
\hline $\begin{array}{l}\text { Risner (2014) } \\
\text { Research in } \\
\text { Dance Education/ } \\
\text { EEUU }\end{array}$ & $\begin{array}{l}\text { Estudio } \\
\text { Mixto }\end{array}$ & $\begin{array}{l}\text { Investigar el bullying y el acoso } \\
\text { de estudiantes adolescentes } \\
\text { hombres de entre } 13 \text { y } 18 \text { años } \\
\text { que cursan clases de danza a } \\
\text { nivel pre-profesionales en } \\
\text { Estados Unidos. }\end{array}$ & $\begin{array}{lrr}\text { Existen visiones } & \text { sobre } \\
\text { masculinización y feminización } \\
\text { de los cuerpos. El conocimiento } \\
\text { corporal y espacial } \\
\text { comprendido, es } \\
\text { profundizado. }\end{array}$ \\
\hline $\begin{array}{l}\text { Melchior (2011) } \\
\text { Research in } \\
\text { Dance Education/ } \\
\text { Nueva Zelanda }\end{array}$ & $\begin{array}{l}\text { Estudio } \\
\text { Cualitativo }\end{array}$ & $\begin{array}{l}\text { Demostrar cómo los profesores } \\
\text { generalistas de primaria pueden } \\
\text { desarrollar estrategias para } \\
\text { enseñar y aprender danza dentro } \\
\text { de contextos significativos y } \\
\text { como parte integral de su } \\
\text { programa de curso. }\end{array}$ & $\begin{array}{l}\text { El conocimiento pedagógico } \\
\text { debe aportar a la comprensión } \\
\text { del conocimiento corporal. }\end{array}$ \\
\hline
\end{tabular}




\begin{tabular}{|c|c|c|c|}
\hline $\begin{array}{l}\text { Egan \& Quigley } \\
\text { (2015) } \\
\text { Research in } \\
\text { Dance Education/ } \\
\text { Nueva Zelanda }\end{array}$ & $\begin{array}{l}\text { Estudio } \\
\text { Mixto }\end{array}$ & $\begin{array}{l}\text { Demostrar cómo la ciencia y la } \\
\text { danza, pueden ayudar a la } \\
\text { recuperación psicológica de } \\
\text { personas que han vivido las } \\
\text { consecuencias de desastres } \\
\text { naturales. }\end{array}$ & $\begin{array}{l}\text { El conocimiento espacial y } \\
\text { corporal es trabajado para } \\
\text { concretizar la inclusión de } \\
\text { movimiento sísmico en la } \\
\text { coreografía. }\end{array}$ \\
\hline $\begin{array}{l}\text { Na, Park \& Han } \\
(2016) \\
\text { Research in } \\
\text { Dance Education/ } \\
\text { Korea del Sur }\end{array}$ & $\begin{array}{l}\text { Estudio } \\
\text { Cualitativo }\end{array}$ & $\begin{array}{l}\text { Promover un programa de danza } \\
\text { que ayude en promover aspectos } \\
\text { físicos, sicológicos } \\
\text { interpersonales, entre las } \\
\text { refugiadas que participan. } \\
\end{array}$ & 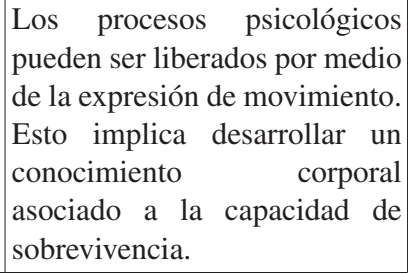 \\
\hline $\begin{array}{l}\text { Misi (2015) } \\
\text { Acta } \\
\text { Ethnographica } \\
\text { Hungarica/ } \\
\text { Hungría }\end{array}$ & $\begin{array}{l}\text { Estudio } \\
\text { Cuantitativo }\end{array}$ & $\begin{array}{l}\text { Cuantificar los movimientos } \\
\text { para generar textos de danza, } \\
\text { para que los estudiantes puedan } \\
\text { trabajar autónomamente. }\end{array}$ & $\begin{array}{l}\text { Ambos conocimientos son } \\
\text { trabajados por medio de la } \\
\text { escritura dancística. La } \\
\text { anotación de una danza permite } \\
\text { que otros puedan aproximarse } \\
\text { a estos conocimientos. }\end{array}$ \\
\hline $\begin{array}{l}\text { Ostern \& Irgens } \\
(2016) \\
\text { Research in } \\
\text { Dance Education/ } \\
\text { Noruega }\end{array}$ & $\begin{array}{l}\text { Estudio } \\
\text { Mixto }\end{array}$ & $\begin{array}{l}\text { Reconocer la influencia de la } \\
\text { pedagogía de la danza en los } \\
\text { procesos coreográficos. }\end{array}$ & $\begin{array}{l}\text { Los estudiantes replican } \\
\text { modelos corporales y } \\
\text { espaciales que fueron } \\
\text { aprendidos de sus maestros. }\end{array}$ \\
\hline $\begin{array}{l}\text { Warnick, Wilt \& } \\
\text { McAdams (2015) } \\
\text { Perfomance } \\
\text { Enhancement \& } \\
\text { Health/EEUU }\end{array}$ & $\begin{array}{l}\text { Estudio } \\
\text { Cualitativo }\end{array}$ & $\begin{array}{l}\text { Conocer las motivaciones, } \\
\text { identidades y experiencias de } \\
\text { bailarines profesionales }\end{array}$ & 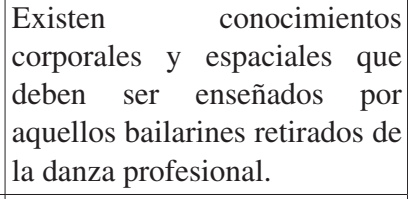 \\
\hline $\begin{array}{l}\text { Henley (2014) } \\
\text { Research in } \\
\text { Dance Education/ } \\
\text { EEUU }\end{array}$ & $\begin{array}{l}\text { Estudio } \\
\text { Cuantitativo }\end{array}$ & $\begin{array}{l}\text { Demostrar que los bailarines } \\
\text { expertos activan fuertemente su } \\
\text { corteza cerebral dorsal durante } \\
\text { la observación de un } \\
\text { movimiento, lo que les permite } \\
\text { replicar un movimiento } \\
\text { observado. }\end{array}$ & $\begin{array}{l}\text { La práctica permite instalar en } \\
\text { la memoria corporal ciertos } \\
\text { movimientos, que pueden ser } \\
\text { identificados claramente por } \\
\text { aquellos bailarines que tienen } \\
\text { experiencia. }\end{array}$ \\
\hline $\begin{array}{l}\text { Zitomer \& Reid } \\
\text { (2011) } \\
\text { Research in } \\
\text { Dance Education/ } \\
\text { Canadá }\end{array}$ & $\begin{array}{l}\text { Estudio } \\
\text { Cualitativo }\end{array}$ & $\begin{array}{l}\text { Determinar las percepciones de } \\
\text { niños con movimiento reducido } \\
\text { entre } 6 \text { y } 9 \text { años sobre las } \\
\text { capacidades (habilidades) que } \\
\text { se requiere para practicar danza. }\end{array}$ & $\begin{array}{l}\text { El conocimiento corporal y } \\
\text { espacial es un conocimiento } \\
\text { que todos pueden aprender, las } \\
\text { dificultades de movilidad no } \\
\text { son elementos negadores de } \\
\text { estos aprendizajes. }\end{array}$ \\
\hline
\end{tabular}


Las 13 investigaciones abordadas en esta categoría de análisis incluyen nuevos lugares de producción de conocimiento espacio-corporales: Nueva Zelanda, Hungría, Korea del Sur y Canadá. Esto permite incluir otras perspectivas, que claramente se traducen en innovaciones a la hora de hablar de formación dancística, justamente es interesante en esta categoría la producción de conocimiento espacio-corporal sea con población variada y no solamente con un sujeto tipo que ya cumple con ciertas condiciones biológico-anatómicas y/o con cierto interés en formarse como profesional de la danza.

La improvisación permite la exploración del entorno que rodea al bailarín, en este sentido se vuelve relevante la investigación de Zitomer \& Reid (2011), quienes trabajan con estudiantes con problema de movilidad y su relación con el espacio. Los ejercicios creativos y de improvisación, permitieron que los niños y niñas se despojaran de los supuestos tradicionales con respecto al cuerpo, enfocando la atención en sus posibilidades de movilidad. Esto permitió que fueran avanzando en seguridad, pero también en relación con la espacialidad circundante. La heterogeneidad de los cuerpos supone experiencias diferenciadas con el espacio, en la investigación realizada por Tsouvala \& Magos (2016), los espacios eran reconocidos por los estudiantes, pero no internalizados, nunca se detuvieron a mirar que sucedía en su entorno, por tanto, el ejercicio de observación les permitió comprender que eran lugares cargados de memoria e identidad. Esto implico que comprendieran que sus cuerpos también eran lugares identitarios. Es importante mencionar que esta es la única investigación que explícitamente intenciona y define el conocimiento espacial y corporal como parte de su estudio.

La experiencia como trayectoria también fue un elemento a considerar en las investigaciones revisadas, pues cuando bailarines con experiencia y sin experiencia se relacionan con el espacio, los resultados coreográficos son distintos. Según Henley (2014), parecería que la experiencia en danza necesariamente se relaciona con el conocimiento corporal, un bailarín con experiencia podría replicar un movimiento visto en una grabación, sabiendo las dimensiones que debe abordar espacialmente. Mientras que el bailarín novato, tendría mayores dificultades. Otra de las dificultades que tienen los bailarines novatos, según Risner (2014), es que aquellos que son hombres sufren durante la adolescencia de bullying, pues el entrenamiento de la danza supone un desarrollo del conocimiento corporal importante, esto implica que algunas prácticas asociadas a la juventud, como la experimentación con drogas, alcohol, entre otras, no sean reproducidas por estos adolescentes/bailarines, lo que inmediatamente los desplaza del grupo. Al mismo tiempo, su memoria corporal va integrando movimientos que sus compañeros no pueden replicar, por tanto, las tensiones van en aumento. Es por esto que, algunos adolescentes/bailarines mantienen un régimen de distanciamiento de sus pares, para enfocarse solamente en su desarrollo corporal, permitiendo compensar su autoestima con logros profesionales.

Las habilidades corporales de un bailarín con experiencia podrían ser más fácilmente desarrolladas por los novatos, si es que existiera una pauta escrita y colectiva de los movimientos necesarios para generar mayor inclinación o elevación, por ejemplo. En el estudio de Misi (2015) la estructura del folclore húngaro posee un tipo de desarrollo corporal y espacial. Más allá de las correcciones dancísticas, aquí es importante considerar la frecuencia de sus movimientos y sus conexiones. El número de acontecimientos de danza consecutivos durante la ejecución de una obra, pueden ser contados, obteniéndose una frecuencia que puede ser digitalizada y luego replicada, generándose un modelo a seguir.

Watson, Nordin-Bates \& Chappell (2012) plantean que todos los conocimientos se van desarrollando, en la medida en que se trabajen supuestos asociados al desarrollo de la 
creatividad, en este caso serían los estilos de enseñanza de los profesores, los que motivarían el aprendizaje de un conocimiento por sobre otro. Koff \& Mistry (2012) ingresan más profundamente en la identidad profesional de los profesores de danza, quienes afirman que su reconocimiento depende del manejo que posean del conocimiento espacial y corporal, esto les permite ser reconocidos por otros y ampliar su estatus y salario.

Aquellos profesores que fueron bailarines profesionales por mucho tiempo tienden según el estudio de Warnick, Wilt \& McAdams (2015), a enfrentar de mejor forma el desafío de enseñar el conocimiento corporal y espacial. Sin embargo, muchas veces sus herramientas de enseñanza son precarias y replican los modelos o estilos pedagógicos con que ellos mismos aprendieron. En este sentido, Ostern \& Irgens (2016), concluyen que efectivamente los modelos instalados por un docente son sumamente fuertes en el aprendizaje de los estudiantes, de esta manera, la identidad individual como bailarín ya está mediada por el liderazgo del profesor que le enseñó a ese bailarín. Sin embargo, si durante la enseñanza, se les entrega el liderazgo a los estudiantes, ellos serían capaces de crear sus propias formas de aproximación a los conocimientos. En el estudio de Melchior (2011) se puede evidenciar, ya que el programa en Educación de la danza para profesores generalistas de escuelas primarias en Aotearoa, Nueva Zelanda, supone que mediante un proceso colaborativo que envuelve pensamiento crítico, enseñar desde las fortalezas que ya existen y el conocimiento pedagógico, al integrar la danza al programa educacional se logra incrementar la conexión entre los profesores y sus alumnos, entre los mismos alumnos, y entre la danza y los estudiantes. De esta forma, el conocimiento corporal y espacial puede ser mucho más significativo.

Es posible observar en el estudio de Egan \& Quigley (2015), que los estudiantes de Hagley Dance Company en Nueva Zelanda, junto a profesionales de la danza, coreografiaron la performance: "Move: A seismic journey" que usó el movimiento humano para representar movimientos sismológicos y geológicos. Los bailarines que vivenciaron el sismo de gran intensidad acontecido un par de años antes en ese lugar, lograron realizar una interpretación corporal que fue muy aplaudida por quienes vieron la presentación. Lo que indica que existe una memoria corporal, que permite re-vivenciar un tipo de movimiento. $\mathrm{Na}$, Park \& Han (2016), revisan las repercusiones de un programa de danza, desarrollado sobre la base de una organización comunitaria para mujeres refugiadas norcoreanas, que viven en Corea del Sur. Los resultados indicaron que la participación en este programa las hizo sentir más integradas al nuevo medio en el que estaban viviendo, además el movimiento corporal incremento en ellas las ansías por mejorar sus vidas y condiciones. Un resultado parecido se obtuvo del estudio de Testa (2012), quien indagó en un taller con enfermos psiquiátricos donde por medio de prácticas dancísticas se pretendía comprender como esta experiencia corporal de liberación, servía para el manejo de la corporalidad por parte de los internos, sin tener que ser una práctica de disciplinamiento del cuerpo. Los resultados indicaron que cada interno participante, comenzó a controlar sus movimientos y actitudes corporales, simplemente porque habían desarrollado conciencia corporal.

Es importante señalar que las 13 investigaciones presentadas, abordan la producción de los conocimientos espacio-corporales desde visiones integradoras, consideran otras opciones en la formación de los bailarines, pero también consideran la apertura de este conocimiento a otras realidades. Deja de pensarse el conocimiento espacio-corporal como una propuesta elitizada a la cual solamente algunos cuerpos pueden acceder o como un conocimiento que se produce solamente desde la juventud y para la juventud. 


\section{DISCUSIÓN}

Una de las primeras brechas encontradas durante esta revisión crítica de literatura, es que las investigaciones empíricas sobre enseñanza de la danza han ido en aumento recién desde el año 2011, lo que supone que el conocimiento corporal y espacial que está en la base de esta disciplina aún no ha sido trabajado en profundidad. Además, las investigaciones han sido desarrolladas preferentemente desde un análisis cualitativo, predominando las perspectivas etnográficas y el análisis de casos. Por otra parte, la concentración de estas investigaciones ha sido en América del Norte y Europa, mientras que los países de América del Sur, Asia y África no presentan tantas publicaciones científicas al respecto. Las investigaciones de aquellos países que son más productivos científicamente también son investigaciones de mayor impacto pues se encuentran asociadas a la base de datos Web of Science y SCOPUS. En el caso específico de América del Sur los artículos se encontraban publicados en la base de datos Scielo, lo que supone un menor impacto de los hallazgos a nivel internacional.

Otra brecha encontrada, y quizás una de las más importante con respecto a la pregunta que dirige esta revisión, es que la enseñanza del conocimiento espacial y del conocimiento corporal, efectivamente se enseña de forma fragmentada. Esto indica que se mantiene el formato tradicional de desarrollo de estos conocimientos. Las dificultades radican justamente en esta dicotomía, solamente algunas investigaciones trabajan ambos conocimientos (Tsouvala \& Magos, 2016). En otros casos existen debilidades con respecto a la enseñanza de ambos conocimientos (Russell-Bowie, 2013; Shue \& Beck, 2001), pues el foco se encuentra posicionado en la competencia y en la ejecución del movimiento, siendo lo más importante, la calificación obtenida y el premio conseguido.

Las formas en que se enseñan estos conocimientos suponen varios elementos, por ejemplo, el trabajo con la memoria corporal es fundamental, ya que es imposible entender como las dimensiones del espacio son aprehendidas por el cuerpo, si es que no se trabaja el cuerpo como un lugar que reconoce ritmos y movimientos. Si bien el conocimiento corporal más técnico, permite que un bailarín reproduzca una frase de movimiento (Watson, Nordin-Bates \& Chappell, 2012; Banerjee, 2013), este movimiento puede estar sin una carga teórica que permita realizar la interpretación apropiada. El conocimiento descontextualizado provoca resquemores a la hora de enseñar danza.

Además, una de las metodologías más utilizadas en la enseñanza de estos conocimientos es la imitación kinética, varias investigaciones (Warnick, Wilt \& McAdams, 2015; Ostern \& Irgens, 2016; Tai, 2014) declaran que los estudiantes de danza sean estos estudiantes de educación primaria, secundaria, superior o del ámbito de la educación no formal, replican o reproducen los movimientos enseñados por sus maestros, adquiriendo características singulares de quien los forma. Es decir, que para la enseñanza de la danza la imitación kinética como metodología es fundamental. Sin embargo, existen otras metodologías que también se pueden/deben trabajar.

Asimismo, es importante destacar la presencia de investigaciones que no se centran en la educación formal, pues pareciera ser que el conocimiento corporal y espacial puede ser aprendido por todas y todos, sin diferenciación de tipos de cuerpo o habilidades previas (Zitomer \& Reid, 2011; Na, Park \& Han, 2016; Egan \& Quigley, 2015; Melchior, 2011; Testa, 2012), de esta forma, la enseñanza de los conocimientos espacio-corporales, puede ser utilizando metodologías propias de la danza, como las actividades lúdicas y la improvisación. 
Es interesante el aporte de algunas investigaciones (Misi, 2015; Sims, Abel, Clasey, Beighle, Fedewa \& Erwin, 2016), con respecto al ingreso de nuevas tecnologías en la optimización de los movimientos e incluso en el desarrollo de procesos de autonomización de las prácticas dancísticas. Es importante considerar, que evidentemente aquellos estudiantes que tienen más años de práctica poseen una confianza y experticia mayor, por tanto, son más proclives a utilizar estas técnicas.

Una tercera brecha, da cuenta de la necesidad que se tiene por fortalecer los aspectos pedagógicos de la enseñanza de la danza (Shue \& Beck, 2001; Lum \& Gonda, 2014; Spagnuolo \& Colket, 2016), claramente haciendo hincapié en que es necesario el conocimiento disciplinar (espacial y corporal) en la formación de los profesores de danza. El elemento más mencionado desde la pedagogía fue la afectividad como forma de enseñar los conocimientos, dejando de lado prácticas asociadas a refuerzos negativos.

Finalmente, la última brecha encontrada posee relación con las macroestructuras que definen la producción del conocimiento espacial y corporal, considerando las decisiones curriculares (Brasileiro, 2013; Tsompanaki, 2014; Tsompanaki \& Benn, 2011) asociadas a la enseñanza de la danza, y las apuestas de revalorización de la cultura nacional (Kaktikar, 2016; Gonye \& Moyo, 2015) por medio de la enseñanza de danzas folclóricas, que poseen un alto componente teórico y de interpretación corporal.

A partir de lo anterior, es posible definir que el conocimiento espacial y corporal en la enseñanza de la danza, se encuentra presente en todas las categorías propuestas para el análisis, si bien muy pocos artículos plantean definidamente cuales son las mejores metodologías para su enseñanza, es posible apreciar que los aspectos anatómicos y teóricos sobre el conocimiento corporal son ampliamente trabajados, predominando los contenidos anatómicos. Mientras que el conocimiento espacial, es trabajado muy pocas veces direccionadamente, aunque inevitablemente se debe abordar en el desarrollo de una coreografía o en la interpretación de un movimiento, pues el trabajo colectivo supone tener claridad en cuanto a la distancia de los cuerpos y al movimiento que se pretende ejecutar. En esta línea las metodologías más utilizadas en la enseñanza de la danza son en primer lugar y como ya se mencionó, la imitación kinética. Mientras que paradojalmente, la segunda en jerarquía es la improvisación. Es interesante, considerar que por un lado se fomenta la repetición del movimiento y por otro, lado se incluyen las propuestas de movimientos propios de los bailarines. No se puede dejar de mencionar que, a la luz de los artículos aquí revisados, la metodología menos utilizada es la creación, al parecer esta metodología solo puede ser puesta en práctica con aquellos estudiantes de formación superior, que ya tienen un entrenamiento en sus cuerpos, es decir, aquellos que ya traen un bagaje con respecto al conocimiento corporal y espacial.

\section{REFERENCIAS BIBLIOGRÁFICAS}

Alarcón, M. (2015). La espacialidad del tiempo: temporalidad y corporalidad en danza. Anales del instituto de investigaciones estéticas, 37(106), 113-147.

Andrada, P. \& Souza, V. (2015). Corpo e docencia: a danca circular como promotora do desenvolvimento da consciencia. Revista Quadrimestral da Associacao Brasileira da Psicologia Escolar e Educacional, 19(2), 359-368.

Banerjee, S. (2013). Adaptation of Bharatanatyam dance pedagogy for multicultural classroom: questions and relevance in a North American university setting. Research in Dance Education, 14(1), 20-38. 
Bannon, F. (2010). Dance: the possibilities of a discipline. Research in Dance Education, 11(1), 49-59.

Bautista, A., Tan, L., Ponnusamy, L. \& Yau, X. (2015). Curriculum integration in arts education: connecting multiple art forms through the idea of "space". Journal of Curriculum Studies, 48(5), 610-629. doi:10.1080/00220272.2015.1089940

Biasutti, M. (2013). Improvisation in dance education: teachers views. Research in Dance Education, 14(2), 120-140.

Brasileiro, L. (2013). Na danca tanto seu objeto quanto seu instrumento profissional é o própio corpo. Revista Brasileira de ciencia e esporte, 35(2), 311-326.

Cámara, E. \& Islas, H. (2007). Pensamiento y acción. El Método Leeder de la Escuela Alemana. México: Editorial del INBA.

Costa, M., Ferreira, A. \& Felicio, L. (2013). Equilibrio estático e dinamico em bailarinos: revisao da literatura. Fisioter pesquisa, 299-305.

Egan, C. \& Quigley, M. (2015). Dancing earthquake science assists recovery from the Christchurch earthquakes. Research in Dance Education, 16(2), 161-183.

Englund, B. \& Sandstrom, B. (2015). "Expression" and verbal expression: on communication in an upper secondary dance class. Research in Dance Education, 16(3), 213-229.

Foucault, M. (2008). Vigilar y castigar. Buenos aires: Siglo Veintiuno Editores.

García-Dantas, A., Caracuel-Tubío, J. \& Peñaloza-Gómez, R. (2012). Intervención formativa con el profesorado de danza e influencia motivacional en su alumnado. Cuadernos de Psicología del Deporte, 13(2), 9-20.

Gonye, J. \& Moyo, N. (2015). Traditional African dance education as curriculum reimagination in postcolonial Zimbabwe: a rethink of policy and practce of dance education in the primary schools. Research in Dance Education, 16(3), 259-275.

Grosz, E. A. (1995). Space, time and perversion: essay on the politics of bodies. United Estates of America: Routledge.

Henley, M. (2014). Is perception of a dance pharse affected by physical movement training and experience? Research in Dance Education, 15(1), 71-82.

Huddy, A. \& Stevens, K. (2011). The teaching artist: a model for university dance teacher training. Research in Dance Education, 12(2), 157-171.

Kaktikar, A. (2016). Dancing in-between spaces: an auto-ethnographic exploration of an abhinaya class. Research in Dance Education. Doi: 10.1080/14647893.1139080

Koff, S. \& Mistry, G. (2012). Professionalism in dance education. Research in Dance Education, 13(1), 83-97.

Laban, R. (2013). Coreografía. Primer cuaderno. México: Editorial del INBA.

Larraín, J. (2014). El concepto de ideología: Volumen 4. Santiago: Editorial LOM.

Lum, C. \& Gonda, D. (2014). Considerations of dance transmission processes: adapting Bharata Natyam in Singapore primary school. Research in Dance Education, 15(2), 107-119.

Mabingo, A. (2015). NYU dance education study abroad program to Uganda: impact on work experiences of study abroad alumni in New York City. Research in Dance Education, 16(2), 99-113.

Massey, D. (2008). Pelo Espaço: uma nova política da espacialidade. Rio de Janeiro: Bertrand Brasil.

Melchior, E. (2011). Culturally responsive dance pedagogy in the primary classroom. Research in Dance Education, 12(2), 119-135.

Miranda, R. \& Cury, V. (2010). Dancar o adolecer: estudo fenomenológico com um grupo de danca de rua em uma escola. Paidéia, 20(47), 391-400.

Misi, G. (2015). Computer-aided dance analysis in practice-with Labanatory. Acta Ethnographica Hungarica, 60(1), 121-170.

McCormack, D. (2008). Geograpfies for Moving Bodies: Thinking, Dancing, Spaces. Geography Compass, 2(6), 1822-1836. 
Na, K., Park, H. \& Han, S. (2016). Designing a community-based dance programme for North Korean female refugees in South Korea. Research in Dance Education, 17(1), 3-13. doi:10.108 $0 / 14647893.2016 .1139076$

Ostern, T. \& Irgens, E. (2016). Interfering with the lived field of dance pedagogy from organizational and leaderships studies perspectives-an explorative intervention with performing and teaching dance artist. Research in Dance Education, 19(1), 57-73. doi:10.1080/14647893.2015.1124079

Pastore, S. \& Pentassuglia, M. (2014). Teaching as dance: A case-study for teacher practice analysis. International Journal of Educational Research, 70, 10-30. http://dx.doi.org/10.1016/j. ijer.2014.12.001

Pulinkala, I. (2011). Integration of a professional dancer into college. Research in Dance Education, 12(3), 259-275.

Risner, D. (2014). Bullying victimisation and social support of adolescent male dance students: an analysis of findings. Research in Dance Education, 15(2), 179-201.

Risner, D. \& Anderson, M. (2015). The Credencial Question: Attitudes of Teaching Artists in dance and Theatre Arts. Teaching Artis Journal, 13(1), 28-35.

Roche, J. \& Huddy, A. (2015). Creative adaptations: integrating Feldenkrais principles in contemporary dance technique to facilitate the transition into tertiary dance education. Theatre, Dance and Performance Training, 6(2), 145-158.

Russell-Bowie, D. (2013). What? Me? Teach dance? Background and confidence of primary preservice teachers in dance education across five countries. Research in Dance Education, 14(3), 216-232.

Sims, M., Abel, M., Clasey, J., Beighle, A., Fedewa, A. \& Erwin, H. (2016). Development of a system for observing dance activities in the classroom enviroment (SODANCE). Research in Dance Education, 17(3), 161-175. Doi: 10.1080/14647893.2016.1150451

Scarpato, M. (2001). Danca educativa: um fato em escolas de sao paulo. Cadernos Cedes, 53, 57-68.

Shue, L. \& Beck, C. (2001). Stepping out of bounds: Performing feminist pedagogy within a dance eduation community. Communication education, 50(2), 125-143.

Spagnuolo, L. \& Colket, L. (2016). Slightly off-balance: learning how to teach anatomical awareness in a dance classroom. Research in Dance Education, 17(2), 86-96. Doi: 10.1080/14647893.2016.1139079

Stanway, A., Bordia, S. \& Fein, E. (2013). Raising the curtain: exploring dancers perceptions of obligation through the psychological contract lens. Arts \& Humanities in Higher Education, 12(3), 254-267.

Styrke, B. (2015). Didactics, dance and teacher knowing in an upper secondary school context. Research in Dance Education, 16(3), 201-212.

Tai, J. (2014). Identities and dance competition: re/discovering the force from within. Research in Dance Education, 15(3), 303-315.

Testa, F. (2012). Uma discreta danca da resistencia: corpo, arte e subjetivacao na oficina de criatividade de um hospoital psiquiatrico. Interface comunicacao, saude e educacao, 16(4), 95-105.

Torrents, C., Castañer, M. Dinusová, M. \& Anguera, T. (2013). Dance divergently in physical education: teaching using open-ended questions, metaphors, and models. Research in Dance Education, 14(2), 104-119.

Tsompanaki, E. (2014). Is there a need for a higher dance institution in Greece? The reality in Greek contemporary dance institutions. Research in Dance Education, 15(39), 271-288.

Tsompanaki, E. \& Benn, T. (2011). Dance students' perceptions of tertiary education in England and in Greece. Research in Dance Education, 12(3), 203-219.

Tsouvala, M. \& Magos, K. (2016) The dance of the magic dragon: embodied knowledge in the context of transformative learning theory. Research in Dance Education. Doi:10.1080/146478 93.2016.1139077

Warnick. J., Wilt, J. \& McAdams, D. (2015). Dancers' stories: A narrative study of profesional 
dancers. Performance Enhancement \& Health. http: //dx.doi.org/10.1016/j.peh.2015.12.002

Watson, D., Nordin-Bates, S. \& Chappell, K. (2012). Facilitating and nurturing crativity in prevocational dancers: Findings from the UK centres for advanced training. Research in Dance Education, 13(2), 153-173.

Zitomer, M \& Reid, G. (2011). To be or not to be- able to dance: integrated dance and children`sperceptions of dance ability and disability. Research in Dance Education, 12(2), 137156. 